\title{
THREE-DIMENSIONAL MECHANICAL MODEL OF THE HUMAN SPINE AND THE VERSATILITY OF ITS USE
}

\author{
Milan SOKOL ${ }^{1}$, Petra VELÍSKOVÁ ${ }^{1}$, L'uboš REHÁK², Martin ŽABKA²
}

\section{Abstract}

The aim of the work is oriented towards the simulation or modeling of the lumbar and thoracic human spine as a load-bearing $3 D$ system in a computer program (ANSYS). The human spine model includes a determination of the geometry based on X-ray pictures of frontal and lateral projections. For this reason, another computer code, BMPCOORDINATES, was developed as an aid to obtain the most precise and realistic model of the spine. Various positions, deformations, scoliosis, rotation and torsion can be modelled. Once the geometry is done, external loading on different spinal segments is entered; consequently, the response could be analysed. This can contribute a lot to medical practice as a tool for diagnoses, and developing implants or other artificial instruments for fixing the spine.
Address

1 Department of Structural Mechanics, Faculty of Civil Engineering, Slovak University of Technology, Radlinského 11, 81368 Bratislava, Slovakia

2 University Hospital in Bratislava, Pažítková 4, 82101 Bratislava, Slovakia

Corresponding author: petra.veliskova@stuba.sk

\section{Keywords}

- Human spine,

- modeling,

- FEM,

- mechanical response.

\section{INTRODUCTION}

The spine of the human body provides several important functions, including protecting the spinal cord and nerves as well as providing structural support for the body, which allows us to stand upright. It is a complex anatomical structure which is the scaffolding for the entire body. Unfortunately, nowadays problems regarding the human spine have arisen. Most of them result in pain; in more serious cases, such as fractures or ruptures of the vertebra or intervertebral disks, even surgery has to be indicated. The pain could have various causes, such as long-term monotonous activity, scoliosis, and accidents, including vertebral body fractures, intervertebral disk displacements, degenerative processes, etc.

Some models of the human spine already exist, but they are quite complicated for daily use in medical practise. Our model of the human spine, based on the finite element method (FEM) using ANSYS computer software, could serve as an aid for relatively easy and quick analyses, predictions, and solving human spine problems for doctors. The model has been designed to copy the geometry of an actual spine as much as possible to obtain the most precise results.

This work is based on previous research (Kenížová, P., 2010), but several improvements have been added.

\section{FEM MODELING}

The principle of the FEM modeling is to generate the horizontal plane of the vertebra upwards. The very first step is to set the plane (Fig. 1.a). The points are defined as nodes which are identified by numbers. Each node has its own $\mathrm{x}, \mathrm{y}$ and $\mathrm{z}$ coordinates.

The next step is to generate the plane upwards to create the column. There are four layers for each intervertebral disk and eight layers for each vertebral body. Taking into account the material properties and anatomy of the spinal components and also the fact that the spinal column is in permanent compression, 
the intervertebral disks were widened, and the vertebral body is narrowed along its height.

When the nodes of the vertebral body are completed, then the nodes of the processes have to be set. Then all the nodes are translated and rotated in each direction, according to the input data, and the elements are created.

The material properties are taken into consideration as well, especially the modulus of elasticity and Poisson`s ratio in each direction. It is very difficult to exactly determine the specific values for the mechanical properties of bones due to numerous natural biological variations. The values from the resources (Brinckmann et al., 2012), (Hakim et al., 1979), (Markolf K.I., 1979) and (Sonnerup, L., 1972) for the cancellous bone, cortical bone, nucleus pulposus and annulus fibrosis were taken into account.

The determination of the dimensions of the spine's geometry ia quite problematic because of the complexity of the human spine (Brinckmann et al., 2012). We can consider the human spine as a column composed of elements - the vertebra and intervertebral disks. In fact, these elements are asymmetrical, and both the vertebral body and the discs increase in size from the head to the sacrum, so the dimensions of each vertebra have to be defined individually. In our case the model is more precise and consists of finite volumetrical and shell elements of every part of the spine, including the vertebra, intervertebral disks, processi spinosi and transversi, muscles, etc. (Fig. 1). Such a model can be used for FEM analysis of stress and displacements; many specific issues such as intervertebral disc slips can be involved too (Fig. 2).

\subsection{Connections}

A particular focus was determined for modelling the connections.

The connection between the vertebra and intervertebral disks was improved in such a way that the possibility of sliding between the vertebral body and intervertebral discs already exists. This is currently modelled by a set of two identical points with the same coordinates (Fig. 2.a). The coupling conditions are defined between them (Fig. 2.b). This satisfies the state of common movements in a normal direction and sliding in a tangential direction of the connection plane. In the future it is planned to introduce friction elements (combin40) (ANSYS, reference manual) between the edge planes of the vertebral body and intervertebral disks. These elements will be able to simulate the friction forces and exsertion of the intervertebral discs.

Articular processi are connections of the vertebrae in the dorsal part. This connection was solved by determining two points (Fig. 3). The free or restricted degrees of freedom are introduced by a coupling command (CP) in ANSYS (ANSYS, reference manual). In such a way it is possible to take into account many variations of joint rotations and also any shifts of the vertebrae.

\subsection{Muscles}

Three types of muscles are modelled - spinotransversal, spinospinal and transversospinal - hinged on the processi (Fig. 4. a)

These muscles are modelled by beam elements (Fig. 1 and Fig. 4.b). A second alternative is to model them by a system of a couple of forces acting towards each other. The idea is to enable them to switch on and off according to their activity and thereby analyse their influence on the spine's response.
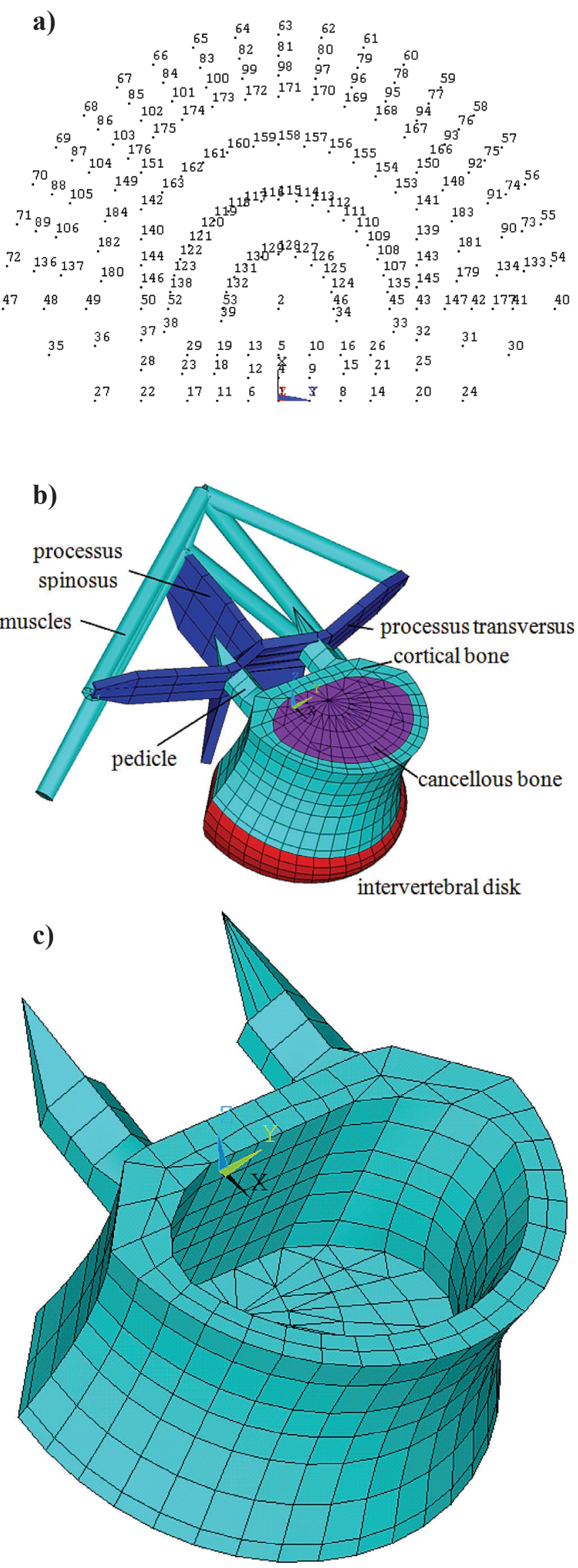

Fig. 1 Modelled a) plane of basic nodes b) FEM model, c) cortical part of vertebra. 
a)

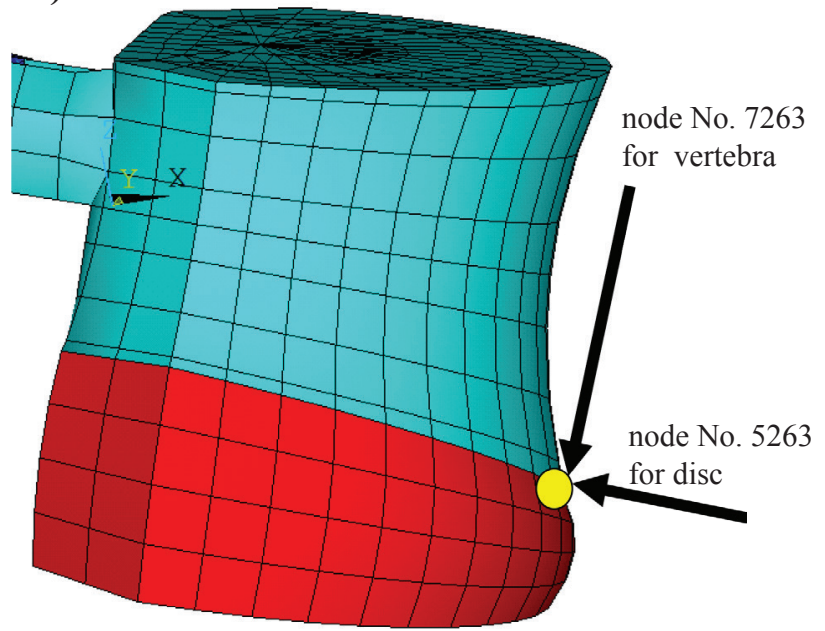

a) scheme of basic nodal numbers

a) scheme of basic nodal numbers b)

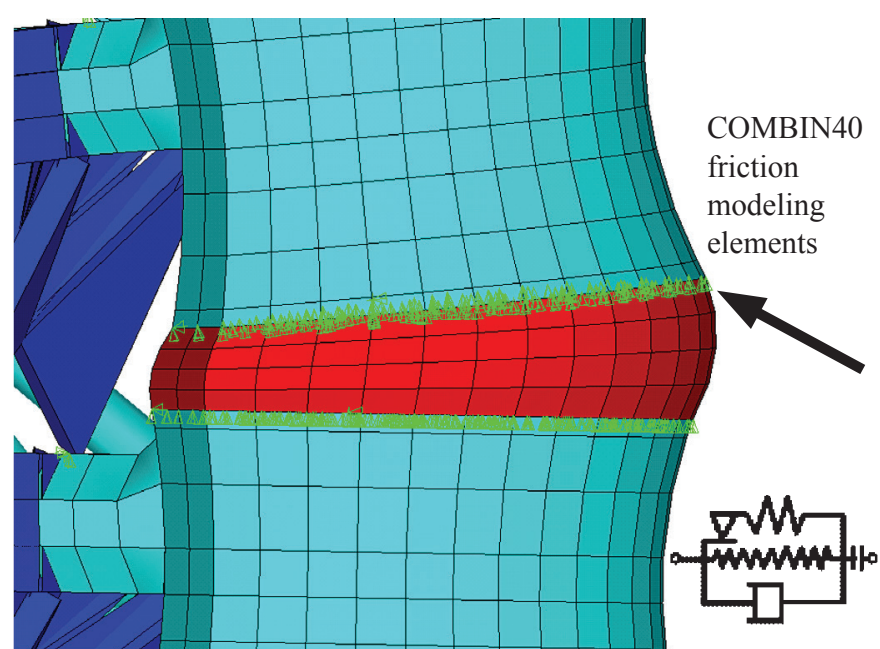

b) couplings (now) or friction el. (future)

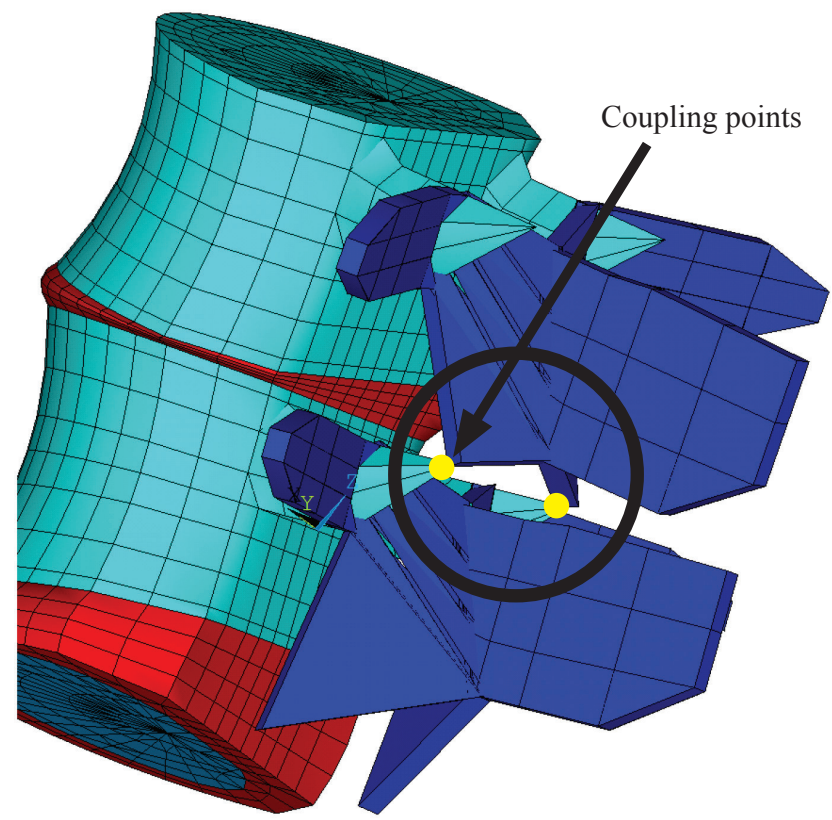

Fig. 3 Connection of the dorsal part of the vertebrae.

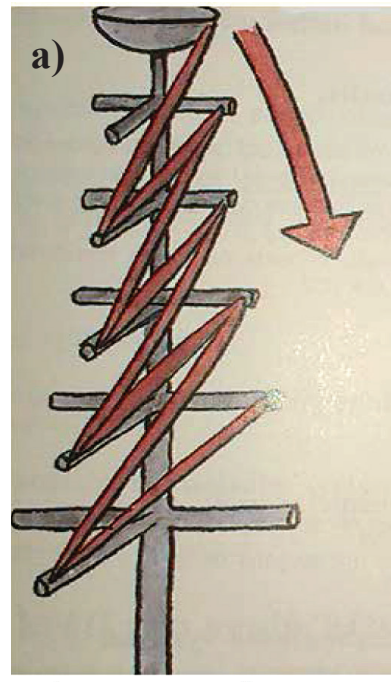

spinotransversal

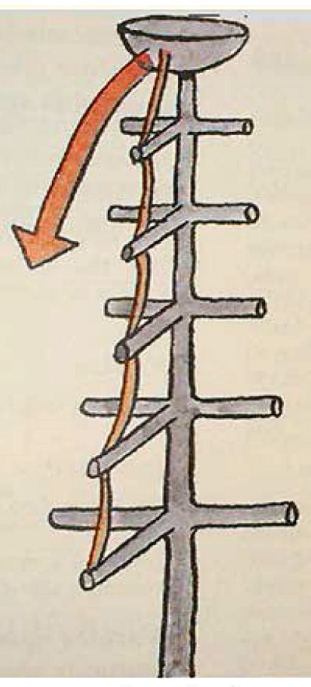

spinospinal

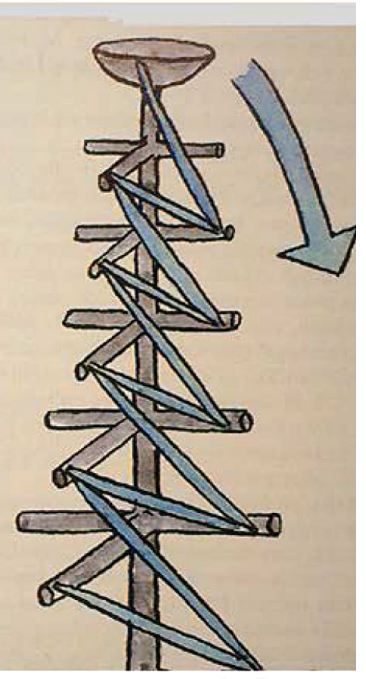

transversospinal

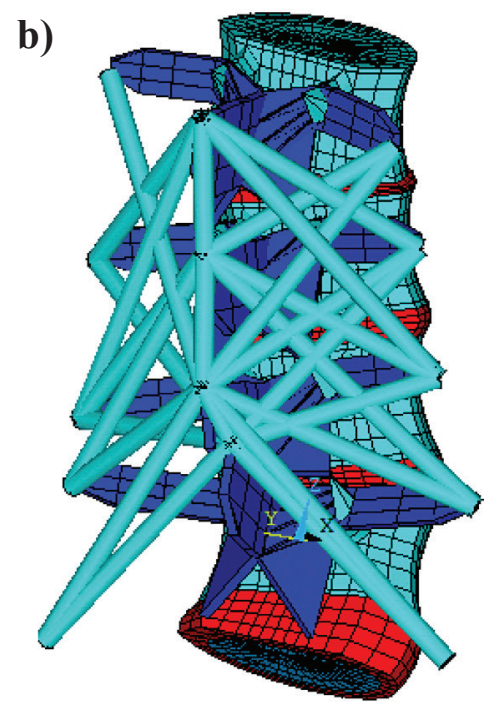

Fig. 4 Muscles a) scheme b) FEM model. 


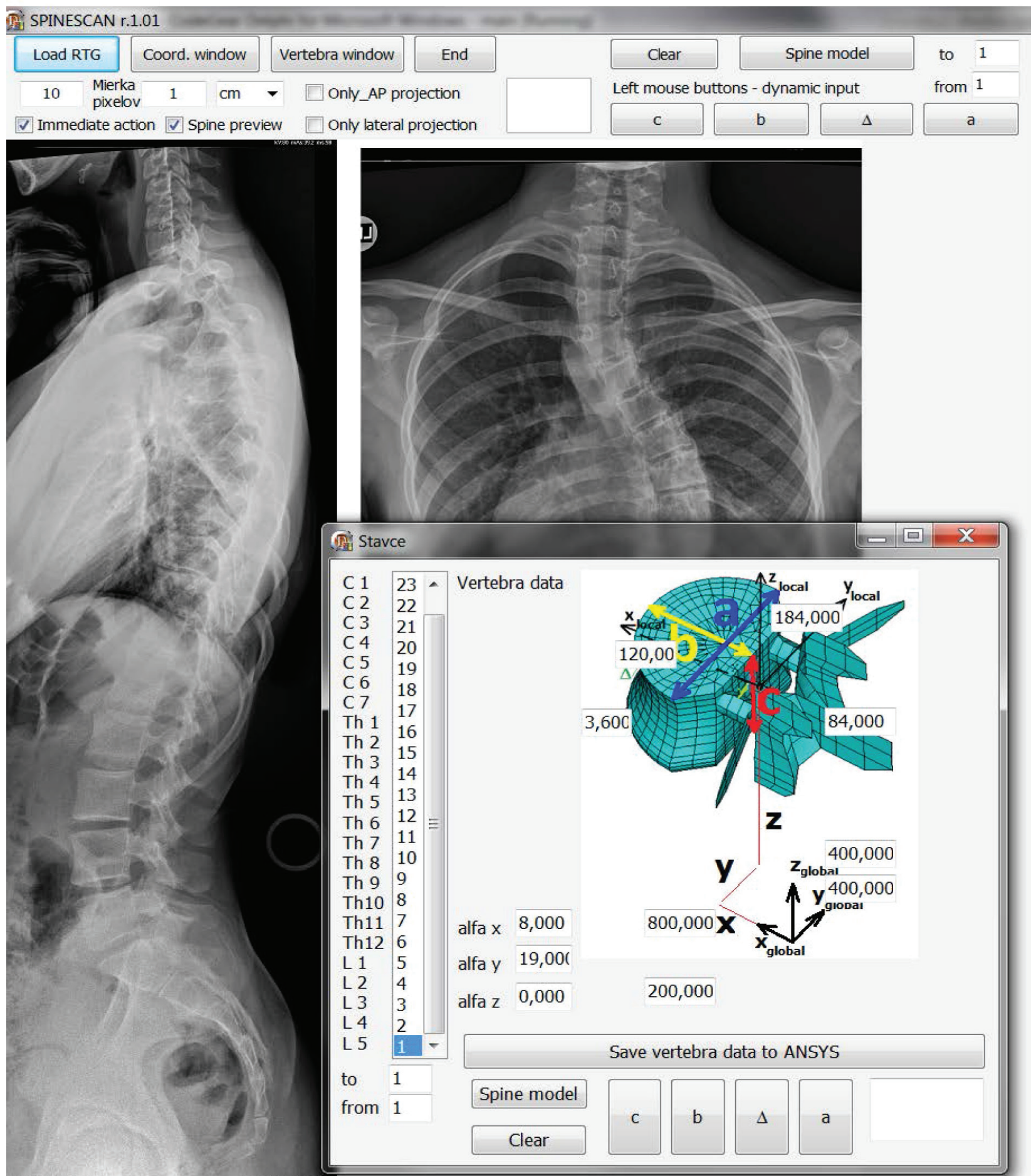

Fig. 5 BMPCOORDINATES program - main menu.

\section{PROGRAMMING INTERFACE BETWEEN THE X-RAY PICTURES AND FEM MODEL}

The main idea is to determine the most precise geometry from the X-rays provided by doctors. A new programme, BMPCOORDINATES, is currently being developed (Fig. 5). The program is able to simultaneously upload two perpendicular projections of a spine - lateral and frontal. Using a mouse, the edge points of the vertebral body are clicked on, and the line representing the length and slope is recorded. These data are exported to ANSYS afterwards, and the spine is modelled.

\subsection{Real time preview}

During the process of setting the data with a PC mouse, the shape of the vertebra is being dynamically depicted on the screen (Fig. 6 and Fig. 7). So the user has control over the whole process.

\section{EXAMPLE OF THE MECHANICAL RESPONSE}

In this section, only a simple example which is intended to confirm the possibility of getting actual mechanical results is presented. More detailed parametric studies will be done in the future. 


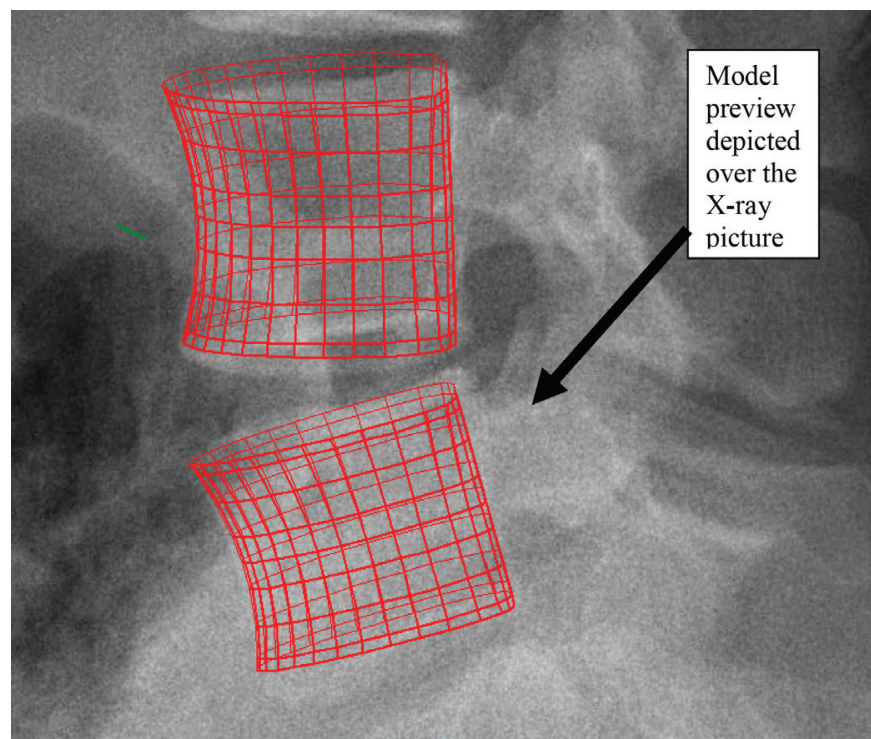

Fig. 6 Real time preview - lateral projection.
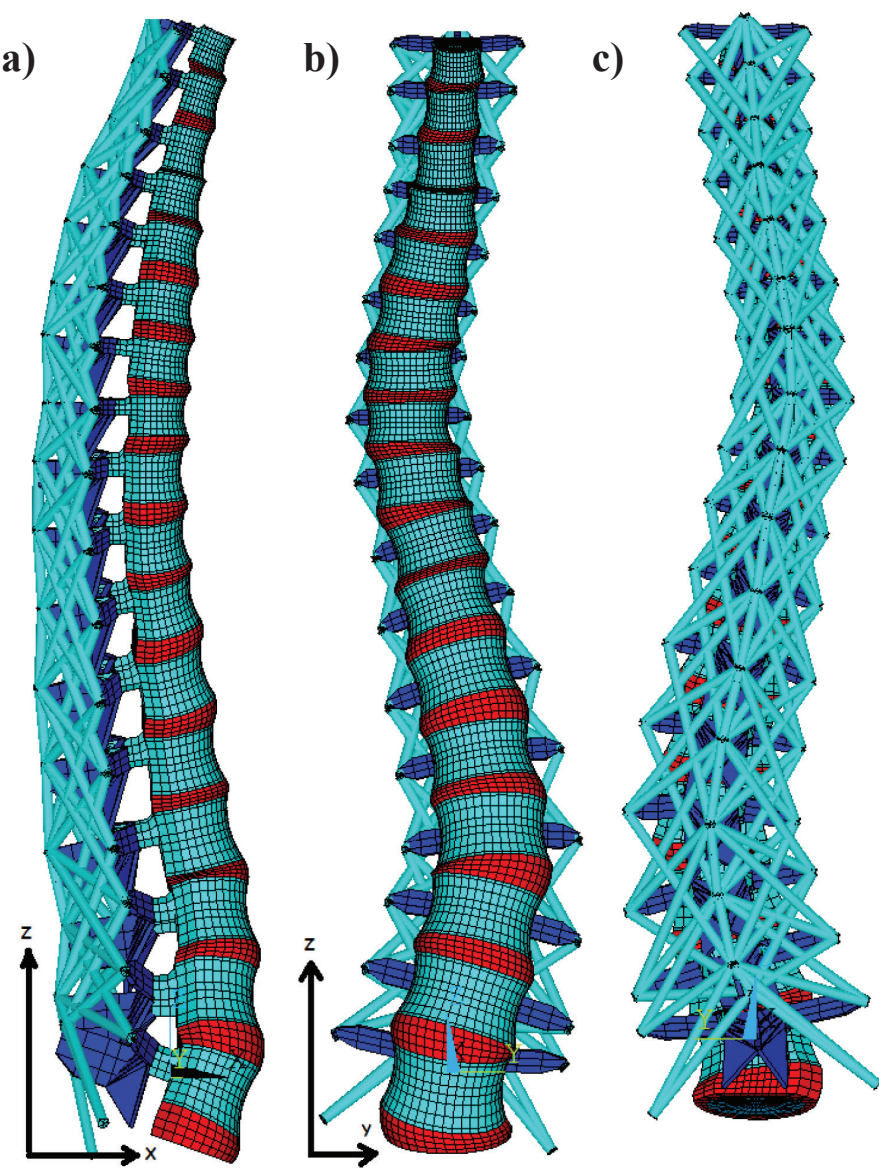

Fig. 8 FEM spine model-scoliosis: a) lateral view b) frontal view c) dorsal view.

An exemplary scoliosis was modelled (Fig. 8), i.e., two curvatures are present both in the $\mathrm{x}$ and $\mathrm{y}$ directions. The one at the $\mathrm{y}$-axis is physiological - lordosis and kyphosis. The second one at the $\mathrm{x}$-axis is pathological - scoliosis.

The vertical gravity force of about half the weight of a patient acting on the upper vertebra in the $\mathrm{z}$-direction was applied; the load of $250 \mathrm{~N}$ was taken into consideration.

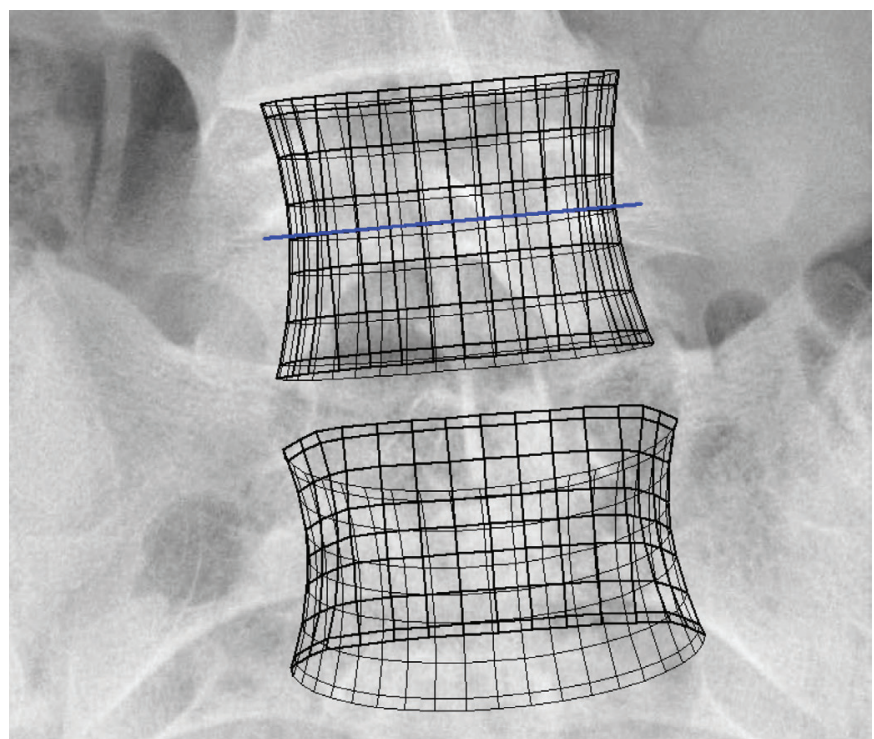

Fig. 7 Real time preview - frontal projection.

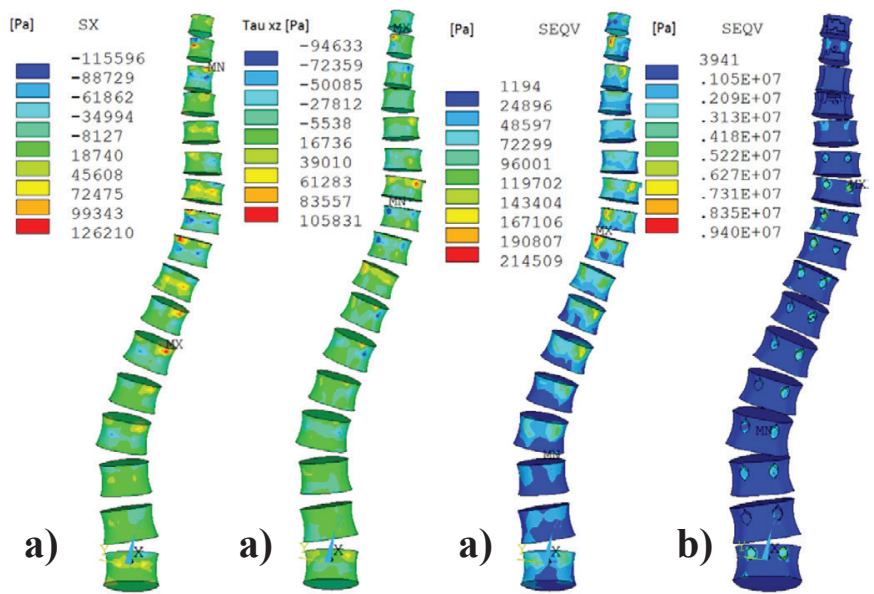

Fig. 9 Stresses in a a) cancellous bone b) cortical bone.
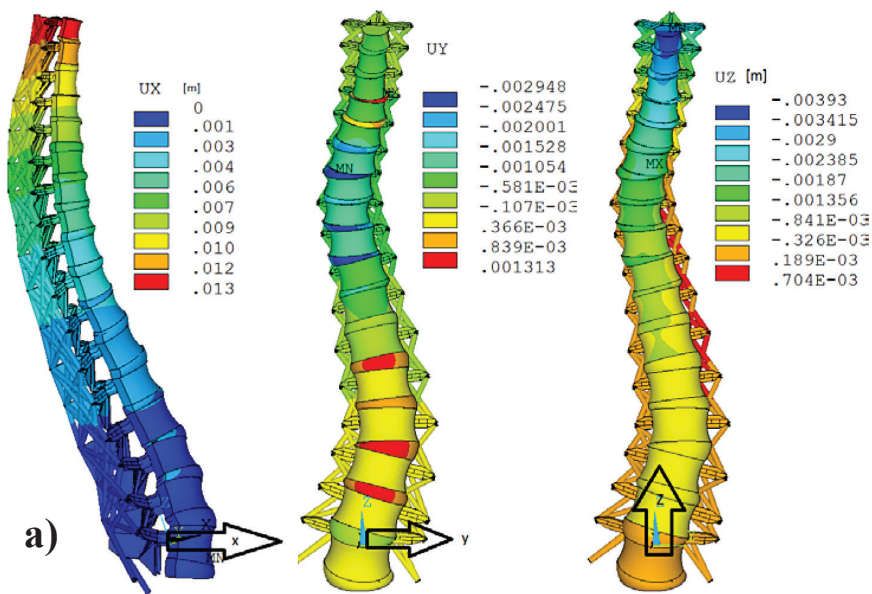

Fig. 10 Displacements a) $U x$ b) $U y$ c) $U z$.

This FEM model consists of about 50,000 nodes and elements and leads to a system of more than 250,000 equations, which can nowadays be solved very quickly (in about 5 minutes).

Using the results of the mechanical response, the rate of the stresses at some parts of the spine can be calculated (Fig. 9.). Displacements of the spine are also available (Fig. 10.). These results can show the areas of possible vertebra ruptures, intervertebral disk displacements, etc. 
It is clear that there are many other results which can be presented too, but this work only shows the ability to quickly and appropriately perform a mechanical modelling of the human spine and check the developing procedures.

\section{CONCLUSION}

The work presented contributes to the mechanical modelling of the human spine. The process for the preparation of an actual mechanical FEM model is divided into two steps. The geometry is defined by the currently developed software BMPCOORDINATES The data from BMPCOORDINATES are exported to ANSYS, where the spine is modelled, and the mechanical response can be analysed relatively quickly.

During the development process, the steps are discussed with doctors (orthopedists), and this system is intended to be used in clinical practice in the future. Some case studies of dynamic loading are planned, and the fixation instruments are also planned to be modelled in the future.

This procedure offers more advantages compared to the oftenused modeling process based on CT records. It is cheaper, and quicker, and the taking of X-rays is not so harmful to the patients.

\section{Acknowledgement}

The authors thank the grant agency of the Ministry of Education, Science, Research and Sports of the Slovak Republic for providing a grant from the VEGA No. 1/1119/11 research program and the OEAD Agency for providing a scholarship grant by the Aktion Österreich-Skowakei.

\section{REFERENCES}

\section{ANSYS, reference manual.}

Brinckmann, P. - Frobin, W. - Leivseth, G. - Drerup, B. (2012) Orthopädische Biomechanik, Wissenschaftliche Schriften. WWU Münster 2012, ISBN 978-3-8405-0059-6.

Čihák, R. (2001) Anatomie 1 (Anatomy 1), Grada Publishing a.s., Prague, ISBN 80-7169-970-5.

Hakim, N. S. - King, A. I. (1979) A 3D Finite Element Dynamic Response Analysis of a Vertebra with Experimental Verification. J. Biomechanics, 12, pp. 277-292.
Kenížová, P. (2010) Biomechanická odozva l’udskej chrbtice na stacionárne silové účinky (Biomechanical response of a human spine concerning stationary force effects). Bratislava, Slovak University of Technology [in Slovak].

Markolf, K. I. (1979) Engineering characteristics of the human intervertebral joint. University of California.

Sonnerup, L. (1972) A semi-experimental stress analysis of an intervertebral disc in compression. Exp. Mech., 12 (3), pp. 122-127. 